\title{
Soluble VCAM-1 and its relation to disease progression in colorectal carcinoma
}

\author{
YOSHINAGA OKUGAWA, CHIKAO MIKI, YUJI TOIYAMA, YUKI KOIKE, TAKESHI YOKOE, \\ SUSUMU SAIGUSA, KOUJI TANAKA, YASUHIRO INOUE AND MASATO KUSUNOKI
}

\author{
Department of Gastrointestinal and Pediatric Surgery, Division of Reparative Medicine, \\ Institute of Life Sciences, Mie University Graduate School of Medicine, Mie 514-8507, Japan
}

Received November 17, 2009; Accepted February 17, 2010

DOI: $10.3892 /$ etm_00000072

\begin{abstract}
The membranous form of vascular cell adhesion molecule (VCAM)-1 supports metastasis, while its soluble forms may suppress cancer growth by competitive inhibition of ligand binding to VCAM-1 and/or by inducing chemotaxis of lymphocytes. Here, we investigated the biological kinetics of membranous and soluble forms of VCAM-1 in tumors, and evaluated their association with malignant potential in colorectal cancer. We measured tissue concentrations of soluble VCAM-1 (sVCAM-1) in tumors and normal mucosa from 150 colorectal cancer patients. VCAM-1 expression was detected immunohistochemically. Reduced levels of sVCAM-1 in cancer tissues were significantly associated with factors reflecting disease progression such as $\mathrm{T}$ classification, lymphatic duct and vessel involvement, lymph node metastasis and distant metastasis. In Cox multivariate analysis, distant metastasis and reduced sVCAM-1 levels in cancer tissues were independent risk factors for poor prognosis. Immunohistochemically, VCAM-1 was intensely expressed in cancer stroma, and its expression was associated with decreased sVCAM-1 concentrations and poor prognosis. Decreased tissue concentrations of sVCAM-1 in colorectal cancer patients were significantly correlated with clinicopathological parameters and prognosis. Suppressed shedding of membranous VCAM-1 in its soluble form into the cancer stroma might play a role in the progression of colorectal carcinoma.
\end{abstract}

\section{Introduction}

Vascular cell adhesion molecule-1 (VCAM-1, CD106) is a 90-kDa glycoprotein containing six or seven immunoglobulin domains. VCAM-1 is a member of the immunoglobulin super-

Correspondence to: Dr Masato Kusunoki, Department of Gastrointestinal and Pediatric Surgery, Division of Reparative Medicine, Institute of Life Sciences, Mie University Graduate School of Medicine, 2-174 Edobashi, Tsu, Mie 514-8507, Japan

E-mail: yosinaga@clin.medic.mie-u.ac.jp

Key words: vascular cell adhesion molecule-1, soluble vascular cell adhesion molecule-1, colorectal cancer, prognostic factor family of adhesion molecules and is constitutively expressed in many different cell types, including activated endothelial cells, bone marrow stromal cells, spleen stromal cells, thymic epithelial cells, peripheral lymph nodes (LNs) and mesenteric LN high endothelial venules $(1,2)$.

It is possible that VCAM-1 is involved in mediating tumor cell adhesion to vascular endothelial cells and promoting the metastatic process (3). VCAM-1-dependent adhesion is known to be responsible for lung metastasis (4). VCAM-1 expression has recently been demonstrated in gastric tumor cells, as well as in tumor-associated endothelial cells, and its expression level is related to invasiveness and advanced stage in gastric tumors (5). However, the mechanism behind the tumorpromoting function of VCAM-1 produced by carcinoma cells is poorly understood. Integrin $\alpha 4 \beta 1$, a partner molecule of VCAM-1, is strongly expressed in the endothelium (6-8), and it is therefore conceivable that endothelial integrin $\alpha 4 \beta 1$ and tumor cell-produced VCAM-1 may play roles in the adhesion of carcinoma cells to the endothelium during the malignant progression of tumors.

Other reports have suggested a mechanism of tumor immune evasion, whereby tumor expression of VCAM-1 may promote T-cell migration away from tumors, resulting in fewer $\mathrm{T}$ cells accumulating in the tumor microenvironment $(9,10)$. This decreased accumulation of $\mathrm{T}$ cells around tumor cells contributes to the ability of VCAM-1-expressing tumor cells to escape immune attack. VCAM-1 is therefore thought to play a key role in the process of malignant progression.

Soluble forms of VCAM-1 (sVCAM-1) have previously been identified (11). It is likely that the soluble products are derived from a range of sources, including enzymatic cleavage from endothelial, leukocyte and tumor cell surfaces, possibly influenced by the intra-tumoral cytokine environment. Elevated serum levels of SVCAM-1 have recently been shown to be associated with disease stage and progression in patients with gastric (8), colorectal (12), breast (13), prostate (14) and bladder (15) cancers, and leukemia (16). In contrast, sVCAM-1 acts as a chemoattractant (17) and competitive inhibitor through interaction with $\alpha 4$ integrins in the local microenvironment (18).

Although many studies have suggested the importance of VCAM-1, the kinetics of the two forms of the molecule have not been investigated. The aim of this study was to evaluate 
the tissue concentrations of SVCAM-1 in colorectal cancer and to clarify its relation to disease progression, with special reference to VCAM-1 expression in the tumor, especially in the cancer cell cytoplasm or cancer stroma.

\section{Patients and methods}

A total of 150 patients undergoing surgery for colorectal cancer from 1996 to 2002 at Mie University Hospital, Japan, were enrolled in this study. Ninety-four of these patients were male. The mean age was 64.9 years (range $37-86$ years). No perioperative mortalities were observed among these patients. No patients had received chemotherapy or radiation therapy prior to surgery.

The location of the tumors and distant metastases were determined by barium enema, colonoscopy, computed tomography (CT) and magnetic resonance image. The primary lesion was located in the rectum in 66 patients, the sigmoid colon in 45 patients, the ascending colon in 27 patients, the transverse colon in 7 patients, and the descending colon in 5 patients. Twenty-eight patients were diagnosed with synchronous liver metastasis and 3 patients with both liver metastasis and peritoneal dissemination. All patients underwent tumor resection and 15 patients underwent simultaneous partial hepatectomy for liver metastasis. Other patients with stage 4 disease had synchronous lung metastasis or peritoneal dissemination. No perioperative mortalities were observed among these patients. Thirteen patients had poorly differentiated adenocarcinomas, while 137 patients had well- or moderately differentiated adenocarcinomas. All patients were classified according to the Union Internationale Contre le Cancer (UICC) classification system, based on resected specimens. There were 37 patients with UICC stage I (T1-2N0M0), 35 patients with UICC stage II (T3-4N0M0), 39 patients with UICC stage III (TXN1-2M0) and 39 patients with UICC stage IV (TXNXM1) disease. Stage III and IV patients received fluorouracil-based chemotherapy, whereas stage I and II patients received no postoperative adjuvant therapy. Patients were observed at 3-month intervals for 24 months after completion of surgery, followed by every 6 months for 3 years, and then yearly. A history was taken and a physical examination was performed at each visit, and chest X-ray, colonoscopy and CT were performed once a year. The median follow-up time was 60.6 months (mean 51.6 \pm 28.4 months). Among the 150 patients studied, 47 died due to primary or recurrent disease. The clinicopathologic parameters studied for their possible prognostic value were $\mathrm{T}$ classification, vessel involvement, lymphatic invasion, lymph node metastases and distant metastasis.

Fresh, operative specimens of the primary colorectal cancer and adjacent normal mucosa, taken $\sim 10 \mathrm{~cm}$ from the neoplasm, were immediately frozen in liquid nitrogen after resection and stored at $-80^{\circ} \mathrm{C}$ until assay and DNA extraction.

Tissue concentrations of sVCAM-1. Surgical specimens were stored in liquid nitrogen until use. Three hundred specimens (150 cancer and 150 normal colorectal mucosa) were prepared for analysis of tissue sVCAM-1 expression. These samples were thawed, quickly weighed, and placed in $5 \mathrm{ml}$ of phosphate-buffered saline (PBS). The tissues were homogenized on ice in $1 \mathrm{ml}$ extraction buffer per $100 \mathrm{mg}$ wet weight of tissue using a motor-driven Teflon pestle for $5 \mathrm{~min}$. The tissue extract obtained after centrifugation at $12,000 \mathrm{rpm}$ for $15 \mathrm{~min}$ at $4^{\circ} \mathrm{C}$ was placed in a $200-\mu \mathrm{l}$ vial and stored at $-80^{\circ} \mathrm{C}$. The concentrations of SVCAM-1 and protein in these tissues were measured in the supernatant, using a commercially available enzyme-linked immunosorbent assay (ELISA) kit (BioSource International, Camarillo, CA, USA). Protein concentrations were measured using a BCA Protein Assay Kit (Pierce Chemical, Rockford, IL, USA). Tissue concentrations were expressed as ng/mg protein. This ELISA was specific for the measurement of sVCAM-1 and did not detect membrane-bound VCAM-1. Informed consent was obtained from each subject. The protocol was approved by the review board of our institute.

Immunohistochemical analysis. Sixty patients were randomly selected for immunohistochemical analysis. Thirty-eight of them were male. The mean age was 63.6 years (range $37-83$ years). There were 14 patients with UICC stage I, 11 with UICC stage II, 19 with UICC stage III and 16 patients with UICC stage IV disease. The median follow-up time was 61.9 months (mean 53.0 \pm 28.3 months). Nineteen of the 60 patients died due to primary or recurrent disease. Paraffin-embedded specimens were cut into 5- $\mu \mathrm{m}$ sections and attached to glass slides with melted wax at $65^{\circ} \mathrm{C}$. The sections were then dewaxed, hydrated and incubated in $3 \%$ hydrogen peroxide for $30 \mathrm{~min}$. The sections were washed in cold tap water, heated in a microwave oven, and washed three times in PBS ( $\mathrm{pH}$ 7.4) for 5 min. After washing with PBS, sections were incubated with primary antibodies overnight at $4^{\circ} \mathrm{C}$. Non-specific binding was blocked by incubation with blocking solution for $1 \mathrm{~h}$ at room temperature. The sections were incubated with a mouse monoclonal antibody raised against VCAM-1 (Santa Cruz, CA, USA) at a dilution of 1:100 overnight at $4^{\circ} \mathrm{C}$ in a moist chamber. The sections were washed and incubated for $30 \mathrm{~min}$ at room temperature with biotinylated anti-rabbit IgG diluted in PBS. The sections were then incubated with avidin/biotin complex reagent for $3 \mathrm{~h}$ at room temperature. The color was developed for $90 \mathrm{sec}$ using a Vector DAB substrate kit and counterstained with Meyer's hematoxylin (Vector Laboratories, Burlingame, CA, USA). The specificity of the immunoreaction was verified by staining known positive and negative control tissue sections, and by negative staining when the primary antibody was replaced by normal mouse serum. The percentage of positively stained tumor cells was evaluated for each tumor section after counting 1,000 cells per high power field. VCAM-1 expression was classified as positive when $>30 \%$ of carcinoma and/or stromal cells were stained. The slides were evaluated three times by three independent investigators who were blinded to the nature of the specimens and antibodies used. This immunohistochemical analysis was specific for the measurement of membrane-bound VCAM-1 and did not detect sVCAM-1.

Statistical analysis. Statistical analysis was performed using StatView software (version 5; Abacus Concepts, Inc., Berkeley, CA, USA). Results are expressed as mean \pm standard deviation (SD). Kruskal-Wallis analysis of variance (ANOVA) 
Table I. Relationships between sVCAM-1 level in cancer tissue and normal mucosa, and clinicopathological factors in 150 colorectal patients.

\begin{tabular}{|c|c|c|c|c|c|}
\hline Variable & No. & $\begin{array}{l}\text { sVCAM-1 level in cancer } \\
\text { tissue (ng/mg protein) }\end{array}$ & p-value & $\begin{array}{l}\text { sVCAM-1 level in normal } \\
\text { mucosa (ng/mg protein) }\end{array}$ & p-value \\
\hline \multicolumn{6}{|l|}{ Gender } \\
\hline Male & 94 & $211.020 \pm 351.170$ & \multirow[t]{2}{*}{$0.3612^{\mathrm{a}}$} & $208.091 \pm 345.779$ & \multirow[t]{2}{*}{$0.8521^{\mathrm{a}}$} \\
\hline Female & 56 & $185.181 \pm 281.170$ & & $199.249 \pm 289.710$ & \\
\hline \multicolumn{6}{|c|}{ Age (years) } \\
\hline$<66$ & 69 & $183.910 \pm 258.153$ & \multirow[t]{2}{*}{$0.7216^{\mathrm{a}}$} & $202.385 \pm 266.340$ & \multirow[t]{2}{*}{$0.4317^{\mathrm{a}}$} \\
\hline$\geq 66$ & 81 & $216.150 \pm 375.327$ & & $206.839 \pm 369.356$ & \\
\hline \multicolumn{6}{|c|}{$\mathrm{T}$ classification } \\
\hline 1 & 14 & $458.792 \pm 669.456$ & \multirow[t]{4}{*}{$0.0086^{b}$} & $204.790 \pm 208.870$ & \multirow[t]{4}{*}{$0.1769^{b}$} \\
\hline 2 & 31 & $191.458 \pm 234.389$ & & $181.049 \pm 162.751$ & \\
\hline 3 & 92 & $165.976 \pm 244.823$ & & $219.171 \pm 392.835$ & \\
\hline 4 & 13 & $198.229 \pm 394.276$ & & $121.283 \pm 125.353$ & \\
\hline \multicolumn{6}{|c|}{ Vessel involvement } \\
\hline+ & 79 & $130.717 \pm 238.577$ & \multirow[t]{2}{*}{$<0.0001^{\mathrm{a}}$} & $148.024 \pm 347.232$ & \multirow[t]{2}{*}{$<0.0001^{\mathrm{a}}$} \\
\hline- & 71 & $279.991 \pm 388.540$ & & $267.953 \pm 287.751$ & \\
\hline \multicolumn{6}{|c|}{$\begin{array}{l}\text { Lymphatic vessel } \\
\text { involvement }\end{array}$} \\
\hline+ & 134 & $178.877 \pm 263.666$ & \multirow[t]{2}{*}{$0.0070^{\mathrm{a}}$} & $199.585 \pm 336.079$ & \multirow[t]{2}{*}{$0.0536^{\mathrm{a}}$} \\
\hline- & 16 & $389.782 \pm 630.259$ & & $248.385 \pm 213.239$ & \\
\hline \multicolumn{6}{|c|}{$\begin{array}{l}\text { Lymph node } \\
\text { metastasis }\end{array}$} \\
\hline N0 & 81 & $256.608 \pm 395.142$ & \multirow[t]{2}{*}{$0.0091^{\mathrm{a}}$} & $226.239 \pm 369.880$ & \multirow[t]{2}{*}{$0.4819^{\mathrm{a}}$} \\
\hline $\mathrm{N} 1$ & 69 & $136.532 \pm 203.358$ & & $179.612 \pm 263.251$ & \\
\hline \multicolumn{6}{|c|}{ Distant metastasis } \\
\hline M0 & 111 & $213.457 \pm 327.157$ & \multirow[t]{2}{*}{$0.0130^{\mathrm{a}}$} & $200.187 \pm 246.763$ & \multirow[t]{2}{*}{$0.2361^{\mathrm{a}}$} \\
\hline M1 & 39 & $166.983 \pm 324.626$ & & $217.893 \pm 487.506$ & \\
\hline \multicolumn{6}{|c|}{$\begin{array}{l}\text { UICC stage } \\
\text { classification }\end{array}$} \\
\hline 1 & 37 & $299.903 \pm 467.795$ & \multirow[t]{4}{*}{$0.0187^{b}$} & $211.157 \pm 186.171$ & \multirow[t]{4}{*}{$0.2264^{b}$} \\
\hline 2 & 35 & $202.431 \pm 286.849$ & & $176.424 \pm 203.953$ & \\
\hline 3 & 39 & $141.338 \pm 127.147$ & & $211.104 \pm 324.736$ & \\
\hline 4 & 39 & $166.983 \pm 324.626$ & & $217.893 \pm 487.506$ & \\
\hline
\end{tabular}

${ }^{\mathrm{a}}$ Mann-Whitney U test; ${ }^{\mathrm{b}}$ Kruskal-Wallis analysis. Values in bold, $\mathrm{p}<0.05$.

and the Mann-Whitney $\mathrm{U}$ test were used to evaluate differences between multiple groups and unpaired observations, respectively. The Spearman rank correlations test was used to determine statistical correlations. Analyses of nonparametric operating characteristics (ROC) were performed to calculate the cut-off values according to the most accurate value obtained using Medcalc 7.2 for Windows (Mariakerke, Belgium). Actuarial survival curves were obtained using the Kaplan-Meier method, and comparisons were made using log-rank tests. The Cox proportional hazards regression model was used for multivariate analysis, after the relevant prognostic variables had been defined by univariate analysis. Contingency tables were analyzed by $\chi^{2}$ tests with Yates' correction. Two-sided p-values $<0.05$ were considered to be statistically significant.

\section{Results}

Tissue levels of sVCAM-1 in cancer and normal mucosa, and their relation to clinicopathological parameters. The concentrations of sVCAM-1 in cancer tissues ranged from 8.8 to $2,611.8 \mathrm{ng} / \mathrm{mg}$ protein, with a mean of $201.4 \pm 326.1 \mathrm{ng} /$ $\mathrm{mg}$ protein. The concentrations of sVCAM-1 in normal mucosa ranged from 18.2 to $3,061.8 \mathrm{ng} / \mathrm{mg}$ protein, with a mean of $204.8 \pm 325.0 \mathrm{ng} / \mathrm{mg}$ protein. The mean sVCAM-1 level in cancer tissue from stage I patients was significantly higher than that from stage III patients (Fig. 1). Table I shows the relationship between tissue concentrations of sVCAM-1 and the clinicopathological findings. The decrease in the concentration of sVCAM-1 in cancer tissues was associated with factors reflecting disease progression, such 
A

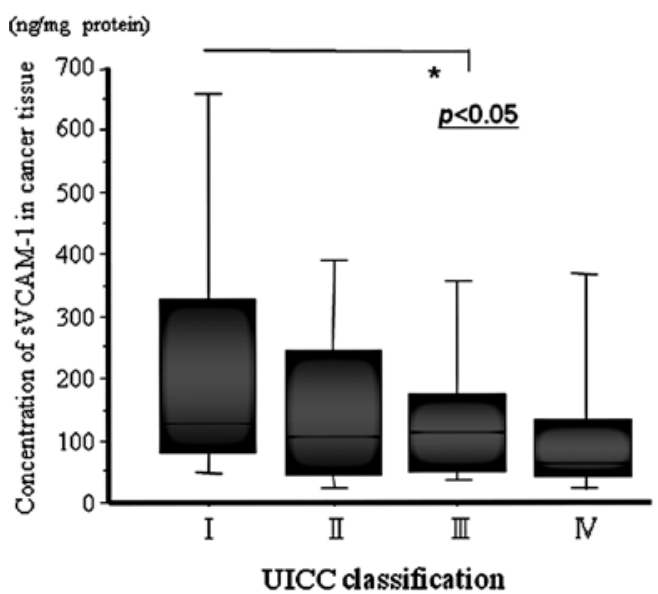

B

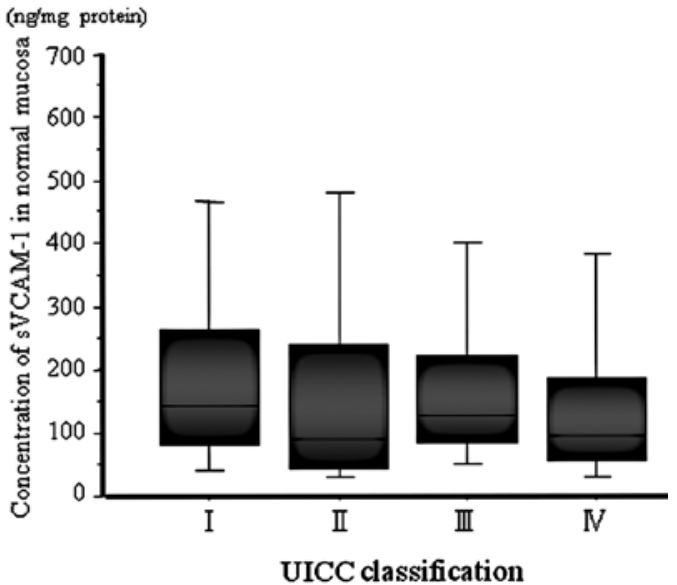

Figure 1. Box plot of (A) tumor and (B) normal tissue levels of sVCAM-1 in 150 colorectal cancer patients.

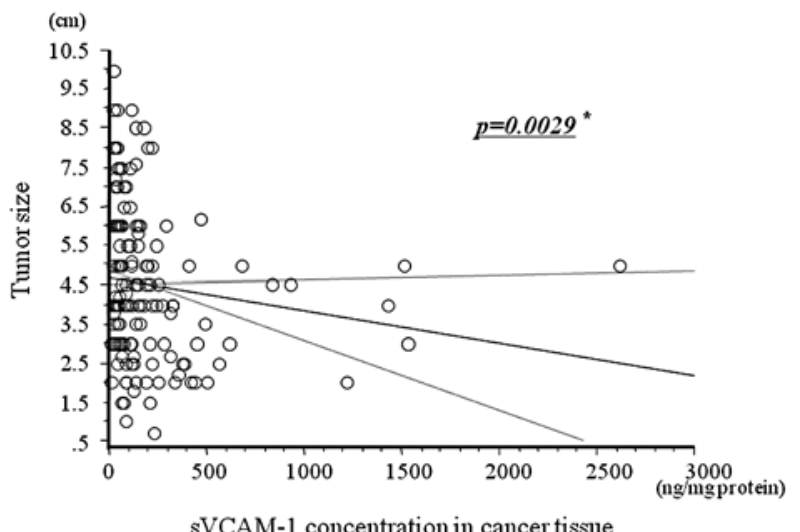

Figure 2. Correlation between tumor tissue levels of sVCAM-1 and tumor size. Tumor tissue levels of sVCAM-1 were negatively correlated with tumor size in colorectal cancer. *Spearman rank correlations test.

as $\mathrm{T}$ classification, vessel involvement, lymphatic vessel involvement, lymph node metastasis and the presence of distant metastasis. In addition, the cancer tissue level of sVCAM-1 decreased significantly in accordance with the progression of UICC classification. In contrast, there was no significant relationship between tissue levels of sVCAM-1 in normal mucosa and disease progression factors, except for vessel involvement.

Relationship between the sVCAM-1 expression level in cancer tissue and tumor size. Fig. 2 shows the relationship between cancer tissue concentrations of SVCAM-1 and tumor size. There was a negative correlation between sVCAM-1 levels in cancer tissues and tumor size $(r=-0.145, p=0.0029)$.

Relationship between sVCAM-1 expression in cancer tissue and the 5-year patient survival. Cut-off points for the tissue concentrations of sVCAM-1 in cancer and normal mucosa were determined using the best pair of values for high sensitivity and high specificity (cancer tissue $111.5 \mathrm{ng} / \mathrm{ml}$ protein, sensitivity $76.6 \%$, specificity $56.3 \%$; normal mucosa $227.3 \mathrm{ng} /$ $\mathrm{ml}$ protein, sensitivity $85.1 \%$, specificity $31.1 \%$ ). Fig. 3 shows

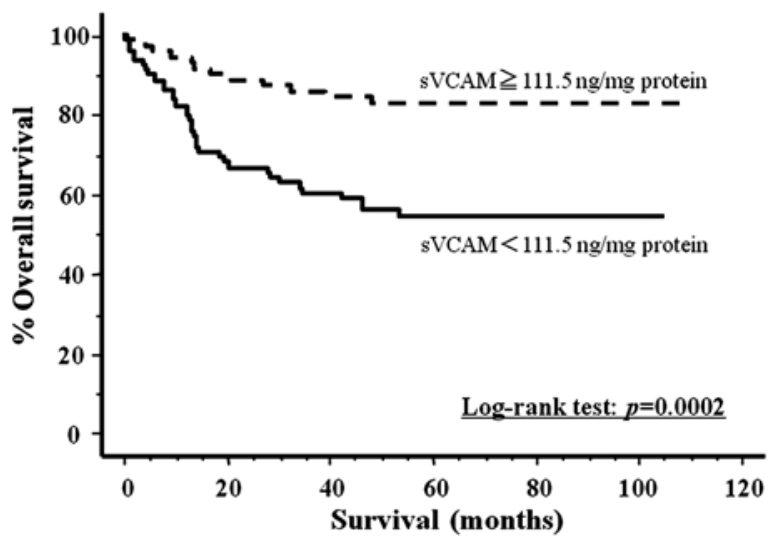

Figure 3. Kaplan-Meier calculation of the actual 5-year survival rates of all patients, with or without decreased tumor tissue levels of sVCAM-1.

the actual survival curves for all colorectal carcinoma patients, subdivided by their tissue levels of sVCAM-1. The patients with lower levels of sVCAM-1 expression had significantly poorer prognoses than those with levels above the cut-off value (log-rank test, $\mathrm{p}=0.0002$ ). Based on Cox univariate proportional hazards analysis, advanced $\mathrm{T}$ classification $(\mathrm{T} 3, \mathrm{~T} 4)$, vessel involvement, lymph node metastasis, distant metastasis and decreased tissue levels of sVCAM-1 were associated with poor prognosis (Table II). Upon multivariate analysis, distant metastasis and decreased tissue sVCAM-1 levels were independent risk factors predicting a poor prognosis (Table III).

Immunohistochemical staining of VCAM-1 in colorectal cancer tissues and its relation to SVCAM-1 levels. Fig. 4A and $\mathrm{B}$ shows the results of the immunohistochemical staining of VCAM-1 in the cancer tissues. VCAM-1 was localized in the cancer stroma (Fig. 4A) and/or the cancer cell cytoplasm (Fig. 4B), especially in vascular endothelial cells. VCAM-1 immunoreactivity in stromal cells was positive in 16 of 60 cases (26.7\%), whereas VCAM-1 immunostaining in cancer cells was observed in only $9(15 \%)$ cases. Fig. $4 \mathrm{C}$ shows the survival curves for the 60 randomly selected patients, subdivided 
Table II. Univariate analysis for predictors of survival in 150 colorectal cancer patients.

\begin{tabular}{|c|c|c|c|}
\hline Variables & HR & $95 \% \mathrm{CI}$ & p-value \\
\hline Gender (male vs. female) & 0.682 & $0.384-1.212$ & 0.1920 \\
\hline Age $(<66$ vs. $\geq 66)$ & 0.855 & $0.479-1.525$ & 0.5958 \\
\hline T classification $(\mathrm{T} 1,2$ vs. T3, 4) & 0.174 & $0.063-0.486$ & $0.0008^{\mathrm{a}}$ \\
\hline Lymphatic vessel involvement (yes vs. no) & 3.067 & $0.743-12.66$ & 0.1213 \\
\hline Vessel involvement (yes vs. no)+ & 2.398 & $1.282-4.484$ & $0.0062^{\mathrm{a}}$ \\
\hline Node involvement (yes vs. no) & 2.874 & $1.567-5.263$ & $0.0006^{\mathrm{a}}$ \\
\hline Distant metastasis (yes or no) & 15.150 & $7.874-28.57$ & $<0.0001^{\mathrm{a}}$ \\
\hline Level of sVCAM-1 in cancer tissue $(\geq 111.5$ vs. $<111.5)$ & 0.309 & $0.160-0.597$ & $0.0005^{\mathrm{a}}$ \\
\hline Level of sVCAM-1 in normal mucosa ( $\geq 227.3$ vs. $<227.3$ ) & 0.491 & $0.229-1.050$ & 0.0666 \\
\hline
\end{tabular}

HR, hazard ratio; CI, confidence interval. ${ }^{\mathrm{a}} \mathrm{p}<0.05$.

Table III. Multivariate analysis for predictors of survival in 150 colorectal cancer patients.

\begin{tabular}{lrrr}
\hline Vaiables & HR & 95\% CI & p-value \\
\hline T classification (T1, 2 vs. T3, 4) & 0.396 & $0.134-1.171$ & 0.0940 \\
Vessel involvement (yes vs. no) & 0.583 & $0.263-1.294$ & 0.1846 \\
Node involvement (yes vs. no) & 0.931 & $0.472-1.838$ & 0.8378 \\
Distant metastasis (yes or no) & 12.820 & $5.917-27.78$ & $<0.0001^{\text {a }}$ \\
Cancer tissue sVCAM-1 level ( $\geq 111.5$ vs. $<111.5)$ & 0.352 & $0.159-0.780$ & $0.0101^{\text {a }}$
\end{tabular}

HR, hazard ratio; CI, confidence interval. ${ }^{\mathrm{a}} \mathrm{p}<0.05$.

Table IV. Relationship between VCAM-1 immunoreactivity and the level of sVCAM-1 in tissue in cancer cell cytoplasm and stroma.

\begin{tabular}{lccccc}
\hline & VCAM-1 immunoreactivity & No. & sVCAM-1 level in cancer tissue & p-value \\
\hline Cancer cell cytoplasm & + & 9 & $136.448 \pm 111.072$ & 0.2421 \\
Cancer stroma & - & 51 & $199.839 \pm 200.978$ & $0.0251^{\mathrm{a}}$ \\
& + & 16 & $108.774 \pm 67.2830$ & $219.998 \pm 212.182$ \\
\hline
\end{tabular}

${ }^{\mathrm{a}} \mathrm{p}<0.05$

according to their cancer stroma VCAM-1 expression levels determined by immunohistochemical analysis. The patients with intense VCAM-1 expression in the stroma had significantly poorer prognoses than those without expression of VCAM-1 (log-rank test, $\mathrm{p}=0.0081$ ). By contrast, there was no correlation between VCAM-1 expression in cancer cell cytoplasm and prognosis (log-rank test, $\mathrm{p}=0.2246$, data not shown). In addition, the mean concentration of sVCAM-1 in the cancer tissue with intense stromal VCAM-1 immunoreactivity was significantly lower than that in the cancer tissue without VCAM-1 expression (108.7 \pm 67.2 vs. $219.9 \pm 212.1 ; \mathrm{p}=0.0251)$, and there was no significant relationship between cancer tissue levels of sVCAM-1 and VCAM-1 immunoreactivity in the cancer cell cytoplasm (Table IV).

\section{Discussion}

In the present study, we determined a strong correlation between decreased SVCAM-1 concentrations in colorectal cancer tissues and disease progression.

Cell adhesion molecules are thought to play an important role in the process of metastasis, since each step requires cell-cell and cell-extracellular matrix interactions (19-21). VCAM-1, one of the most important adhesion molecules, exists as a membrane-bound and a soluble form, and plays a crucial role in this process $(3,4)$. Other reports have suggested a mechanism of tumor immune evasion whereby tumor expression of VCAM-1 might promote T-cell migration away from tumors, therefore allowing them to escape immune 
A

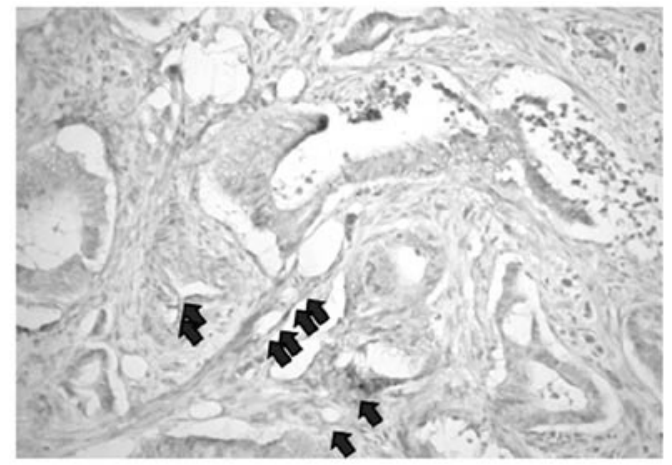

B

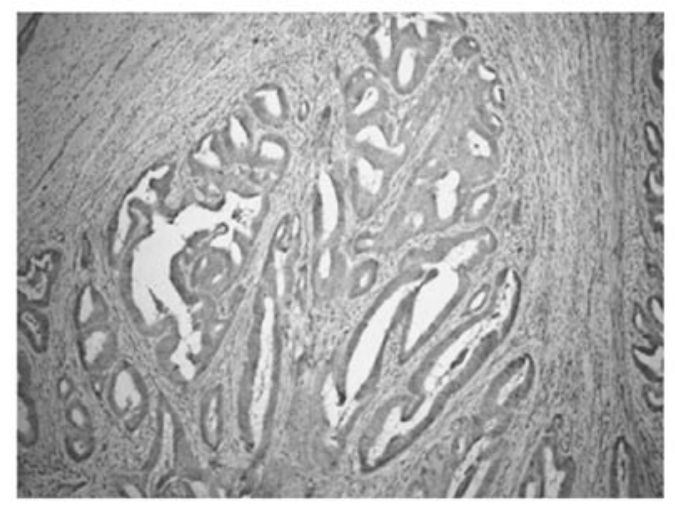

C

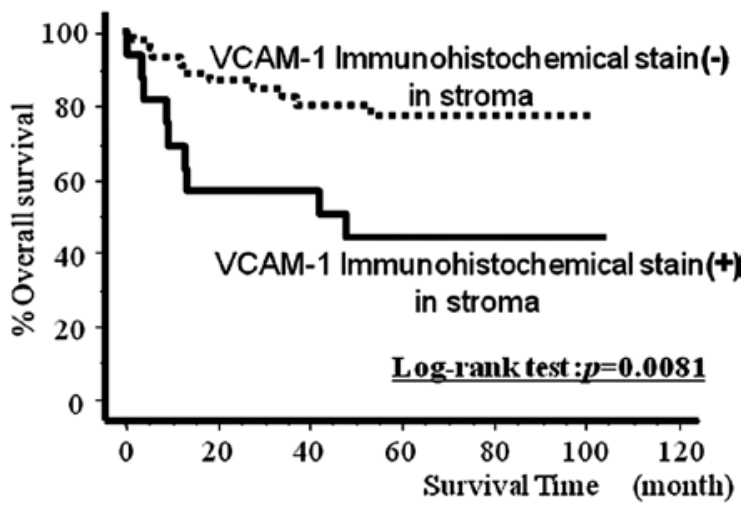

Figure 4. Typical example of positive immunohistochemical staining of VCAM-1 in colorectal cancer stroma (A, arrows; original magnification $\mathrm{x} 100)$ and cancer cell cytoplasm (B; original magnification x100). KaplanMeier plots illustrating associations between VCAM-1 expression in cancer stroma and overall survival (C).

attack $(9,10)$. VCAM-1 is thus considered to play a key role in the process of malignant progression. A previous study using Northern blotting revealed that VCAM-1 mRNA was overexpressed in colorectal cancer, in comparison to normal controls (22). It has also been demonstrated that VCAM-1 expression in gastric cancers is highly related to invasiveness and advanced stage (5).

In contrast, sVCAM-1 has been found in the culture supernatants of cytokine-treated endothelial cells in human serum and in the synovial fluid of patients with rheumatoid arthritis $(23,24)$. The origin of sVCAM-1 is not completely understood, but it is possible that it is released from the cell surface by proteolytic cleavage (25). sVCAM-1 could act as a chemoattractant (17) and competitive inhibitor through interaction with $\alpha 4$ integrins in the local microenvironment (18). Although it is possible that sVCAM-1 itself may inhibit cancer growth, there have been no reports on the function of sVCAM-1 itself in the colorectal cancer microenvironment.

In the present study, reduced levels of sVCAM-1 in cancer tissues were significantly correlated with well-known prognostic factors such as T classification, lymphatic duct and vessel involvement, nodal metastasis and distant metastasis. By contrast, there was no significant relationship between the levels of sVCAM-1 in normal mucosa and clinicopathological factors, except for vascular involvement. Patients with decreased cancer tissue levels of sVCAM-1 had significantly poorer prognoses than those with higher levels. Furthermore, a decreased cancer tissue level of sVCAM-1 and distant metastasis were found to be independent prognostic factors for colorectal carcinomas. These data strongly suggest that decreased cancer tissue levels of sVCAM-1 are intimately involved in the process of tumor progression. The negative correlation between SVCAM-1 expression in cancer tissues and tumor size may also be explained by the promotion of local cancer growth by sVCAM-1 itself.

Notably, the present study showed that decreased sVCAM-1 cancer tissue concentrations were associated with positive expression of VCAM-1 in the cancer stroma, but not in the cancer cell cytoplasm, suggesting that concentrations of sVCAM-1 in cancer tissue mainly reflect the shedding of membranous VCAM-1 from tumor stromal cells.

The shedding of VCAM-1 from cytokine-stimulated endothelial cell surfaces is regulated by tissue inhibitor of metalloprotease-3, which is mediated by tumor necrosis factor- $\alpha$-converting enzyme (ADAM17) (26,27). BlanchotJossic et al found that ADAM17 was present in an active form and was up-regulated at the mRNA level in primary colon carcinomas compared with paired normal colonic mucosa. In addition, ADAM17 was expressed by stroma cells, i.e. some immune cells, vascular and non-vascular myocytes, and by some endothelial cells, but not by cancer cells (28). The association between the expression of VCAM-1 in the cancer stroma and the concentration of SVCAM-1 found in our study might suggest that shedding, resulting from proteolytic cleavage of the cancer membrane-bound molecule, occurs in the cancer microenvironment. It is therefore conceivable that shedding of VCAM-1 into the cancer microenvironment as a result of proteolytic cleavage could influence cancer progression and prognosis both by suppressing the VCAM-1 pathway and by the competitive activity of sVCAM-1 itself.

In conclusion, we demonstrated that decreased tissue concentrations of sVCAM-1 in colorectal cancer patients were significantly correlated with clinicopathological parameters and prognosis. Although the regulatory mechanisms of the membranous and soluble forms of VCAM-1 are currently unknown, the present results suggest that the induction of proteolytic cleavage could provide a potential immunological basis for possible future cancer treatment strategies.

\section{Acknowledgements}

The authors would like to thank Hiromi Ueeda and Yuka Kato for their excellent technical assistance. 


\section{References}

1. Norris P, Poston RN, Thomas DS, Thornhill M, Hawk J and Haskard DO: The expression of ELAM-1, ICAM-1 and VCAM-1 in experimental cutaneous inflammation: a comparison of UVb erythema and delayed hypersensitivity. J Invest Dermatol 96 763-970, 1991.

2. Yoo NC, Chung HC, Chung HC, et al: Synchronous elevation of soluble intracellular adhesion molecule-1 (ICAM-1) and vascular cell adhesion molecule-1 (VCAM-1) correlates with gastric cancer progression. Yonsei Med J 39: 27-36, 1998.

3. Shin J, Kim J, Ryu B, Chi SG and Park H: Caveolin-1 associated with VCAM-1 dependent adhesion of gastric cancer cells to endothelial cells. Cell Physiol Biochem 17: 211-220, 2006.

4. Higashiyama A, Watanabe $\mathrm{H}$, Okumura $\mathrm{K}$ and Yagita $\mathrm{H}$ : Involvement of tumor necrosis factor alpha and very late activation antigen 4/vascular cell adhesion molecule 1 interaction in surgical-stress enhanced experimental metastasis. Cancer Immunol Immunother 42: 231-236, 1996.

5. Ding YB, Chen GY, Xia JG, Zang XW, Yang HY and Yang L: Association of VCAM-1 overexpression with oncogenesis, tumor angiogenesis and metastasis of gastric carcinoma. World $\mathbf{J}$ Gastroenterol 9: 1409-1414, 2003.

6. Velikova G, Banks RE, Gearing A, et al: Circulating soluble adhesion molecules E-cadherin, E-selectin, intracellular adhesion molecule-1 (ICAM-1) and vascular cell adhesion molecule-1 (VCAM-1) in patients with gastric cancer. Br J Cancer 76: 1398-1404, 1997.

7. Gulubova MV: Expression of cell adhesion molecules, their ligands and tumor necrosis factor alpha in the liver of patients with metastatic gastrointestinal carcinomas. Histochem J 34: 67 , 2002.

8. Alexiou D, Karayiannakis AJ, Syrigos KN, et al: Clinical significance of serum levels of E-selectin, intracellular adhesion molecule-1 and vascular cell adhesion molecule-1 in gastric cancer patients. Am J Gastroenterol 98: 478-485, 2003.

9. Kobayashi H, Boelte KC, and Lin PC: Endothelial cell adhesion molecules and cancer progression. Curr Med Chem 14: 377-386, 2007.

10. Wu TC: The role of vascular cell adhesion molecule-1 in tumor immune evasion. Cancer Res 67: 6003-6006, 2007.

11. Gearing AJ, Hemingway I, Pigott R, Hughes J, Rees AJ and Cashman SJ: Soluble forms of vascular adhesion molecules, E-selectin, ICAM-1 and VCAM-1: pathological significance. Ann NY Acad Sci 667: 324-331, 1992.

12. Alexiou D, Karayiannakis AJ, Syrigos KN, Zbar A, Kremmyda A Bramis I and Tsigris C: Serum levels of E-selectin, ICAM-1 and VCAM-1 in colorectal cancer patients: correlations with clinicopathological features, patient survival and tumor surgery. Eur J Cancer 37: 2392-2397, 2001.

13. O'Hanlon DM, Fitzsimons H, Lynch J, Tormey S, Malone C and Given HF: Soluble adhesion molecules (E-selectin, ICAM-1 and VCAM-1) in breast carcinoma. Eur J Cancer 38: 2252-2257, 2002.
14. De Cicco C, Ravasi L, Zorzino L, et al: Circulating levels of VCAM and MMP-2 may help identify patients with more aggressive prostate cancer. Curr Cancer Drug Targets 8: 199-206, 2008.

15. Coskun U, Sancak B, Sen I, Bukan N, Tufan MA, Gülbahar O and Sozen S: Serum P-selectin, soluble vascular cell adhesion molecule-I (s-VCAM-I) and soluble intercellular adhesion molecule-I (s-ICAM-I) levels in bladder carcinoma patients with different stages. Int Immunopharmacol 6: 672-677, 2006.

16. Christiansen I, Sundstrom C and Totterman TH: Elevated serum levels of soluble vascular cell adhesion molecule-1 (sVCAM-1) closely reflect tumour burden in chronic B-lymphocytic leukemia. Br J Haematol 103: 1129-1137, 1998.

17. Shimizu Y, Newman W, Gopal TV, et al: Four molecular pathways of T cell adhesion to endothelial cells: roles of LFA-1, VCAM-1 and ELAM-1 and changes in pathway hierarchy under different activation conditions. J Cell Biol 113: 1203-1212, 1991.

18. Makarem R, Newham P, Askari JA, et al: Competitive binding of vascular cell adhesion molecule-1 and the HepII/IIICS domain of fibronectin to the integrin alpha 4 beta 1 . J Biol Chem 269: 4005-4011, 1994

19. Albelda SM: Role of integrins and other cell adhesion molecules in tumor progression and metastasis. Lab Invest 68: 4-17, 1993.

20. Ponta H, Sleeman J and Herrlich P: Tumor metastasis formation: cell-surface proteins confer metastasis-promoting or -suppressing properties. Biochem Biophys Acta 1198: 1-10, 1994.

21. Ohene-Abuakwa Y and Pignatelli M: Adhesion molecules as diagnostic tools in tumor pathology. Int J Surg Pathol 8: 191-200, 2000.

22. Maurer CA, Friess H, Kretschmann B, et al: Overexpression of ICAM-1, VCAM-1 and ELAM-1 might influence tumor progression in colorectal cancer. Int J Cancer 79: 76-81, 1998.

23. Lloyd AR, Oppenheim JJ, Kelvin DJ and Taub DD: Chemokines regulate $\mathrm{T}$ cell adherence to recombinant adhesion molecules and extracellular matrix proteins. J Immunol 156: 932-938, 1996.

24. Kitani A, Nakashima N, Matsuda T, Xu B, Yu S, Nakamura T and Matsuyama T: T cells bound by vascular cell adhesion molecule-1/CD106 in synovial fluid in rheumatoid arthritis: inhibitory role of soluble vascular cell adhesion molecule-1 in T cell activation. J Immunol 156: 2300-2308, 1996.

25. Masumoto A and Hemler ME: Multiple activation states of VLA-4. Mechanistic differences between adhesion to CS1/ fibronectin and to vascular cell adhesion molecule-1. J Biol Chem 268: 228-234, 1993.

26. Garton KJ, Gough PJ, Philalay J, et al: Stimulated shedding of vascular cell adhesion molecule 1 (VCAM-1) is mediated by tumor necrosis factor-alpha-converting enzyme (ADAM 17). J Biol Chem 278: 37459-37464, 2003.

27. Singh RJ, Mason JC, Lidington EA, et al: Cytokine stimulated vascular cell adhesion molecule-1 (VCAM-1) ectodomain release is regulated by TIMP-3. Cardiovasc Res 67: 39-49, 2005.

28. Blanchot-Jossic F, Jarry A, Masson D, et al: Up-regulated expression of ADAM17 in human colon carcinoma: co-expression with EGFR in neoplastic and endothelial cells. J Pathol 207: 156-163, 2005. 